Article

\title{
An R\&D Management Framework for Eco-Technology
}

\section{Hideki Kobayashi $^{1, *}$, Masahiro Kato ${ }^{1}$, Yukishige Maezawa ${ }^{2}$ and Kenji Sano ${ }^{1}$}

1 Corporate R\&D Center, Toshiba Corporation. 1, Komukai-Toshiba-cho, Saiwai-ku, Kawasaki 2128582, Japan; E-Mails: shonan.kato@toshiba.co.jp (M.K.); kenji.sano@toshiba.co.jp (K.S.)

2 Belonging to the above organization at that time the research reported in this paper was conducted; E-Mail: yukishige.maezawa@toshiba.co.jp

* Author to whom correspondence should be addressed; E-Mail: hide.kobayashi@toshiba.co.jp; Tel.: +81-44-549-2068; Fax: +81-44-549-2468.

Received: 28 April 2011; in revised form: 14 July 2011 / Accepted: 16 August 2011 /

Published: 24 August 2011

\begin{abstract}
Although research and development (R\&D) affects new value-added creation, including that related to environmental aspects, there is little literature dealing with the integration of R\&D management and eco-value. Here, eco-value of technology is defined as the advantage of environmental competitiveness in the market. This paper proposes a framework of R\&D management of eco-technology (RDMOET), consisting of: (1) future research for sustainability; (2) making an original eco-theme portfolio and roadmap; (3) gap analysis and implementation of new eco-themes; and (4) eco-value evaluation. (1) and (4) are new processes compared with conventional R\&D management. Through practice at the Corporate $\mathrm{R} \& \mathrm{D}$ Center of Toshiba Corporation, the usefulness of the proposed framework is verified from the viewpoint of not only technological eco-innovation, but also that of organizational learning for environmental sustainability.
\end{abstract}

Keywords: R\&D management; management of eco-technology; future research; eco-value evaluation; organizational learning

\section{Introduction}

Environmental consciousness of products, services and businesses has become an increasingly important issue for enterprise management. In recent years, the emphasis of enterprises' environmental 
countermeasures has been shifting from a reactive to a proactive posture. For example, whereas the former approach implies adapting products and their manufacturing processes to new environmental regulations, the latter approach implies creation of products and services offering new value in terms of environmental performance, namely, through eco-innovation. In order to realize environmental consciousness of a product and its life cycle, design and post-design processes have to be managed appropriately by a company or a group of companies (Figure 1). Many eco-design methodologies and software tools have been developed, and some of these are utilized in industry [1-3]. After the design phase, devices and information systems for product lifecycle monitoring and management are also introduced step by step [4,5].

Figure 1. Product lifecycle process and scope of this paper.

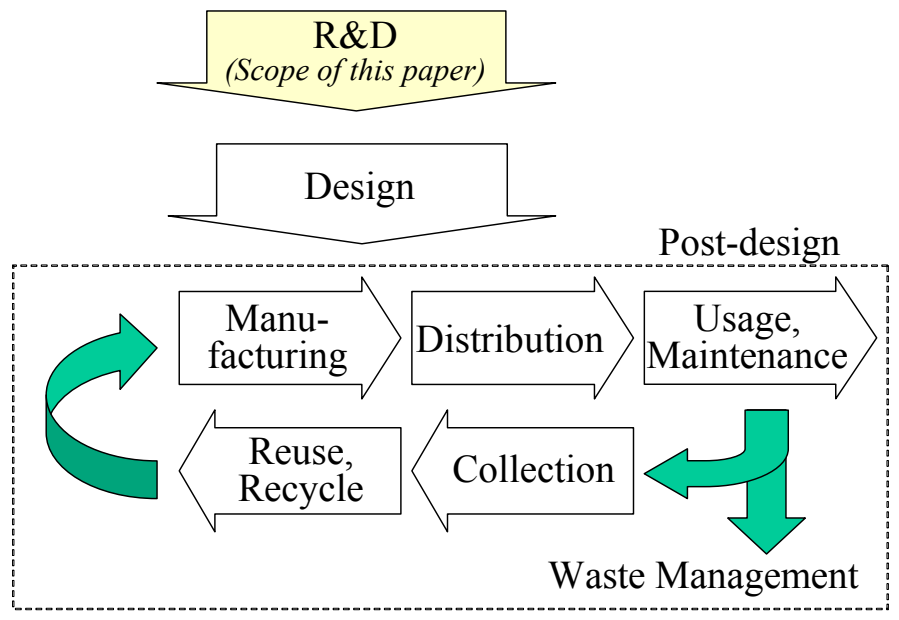

Clearly, research and development (R\&D) in manufacturing companies is one of the key issues concerning innovation. Thus, the importance of environmental considerations in R\&D concerning new elements of technology is increasing as companies seek to promote eco-innovation. However, to our knowledge, there are very few reports dealing with the relationship between environmental pressures and $R \& D$ management.

The objective of this paper is to propose a framework of $R \& D$ management of eco-technology (RDMOET), which provides technical methods and a learning structure for an eco-innovative R\&D organization. The remainder of this paper is organized as follows. Section 2 refers to related works and presents our approach. In Section 3, a framework of RDMOET is proposed. In Section 4, some examples of RDMOET at the Corporate R\&D Center of Toshiba Corporation are introduced. After considering what has been learned through the practice of RDMOET, we summarize this paper.

\section{Related Work and This Study's Approach}

\subsection{Related Work}

\subsubsection{Future Research for Sustainability}

Future research is one of the important bases for technology development, policy making and social design [6]. It is not simply economic projection, sociological analysis or technological forecasting, but 
a multidisciplinary examination of change in all major areas of life to find the interacting dynamics that are creating the next era. In the field of environmental sustainability, long-term vision and direction play important roles, unlike in market research based on short- or medium-range estimation. Various scenarios for accomplishing long-term environmental targets have been developed at the global level

[7-9]. However, it is difficult to compare the various scenarios because the assumptions embedded in them are complicated and not explicit in some cases. Since there are also cases in which a sustainable future is envisioned without engineering rigor, the importance of articulating a clear vision underpinned by engineering rigor, or "Visioneering" [10], has been pointed out. Sustainability science is an academic discipline that aims to secure the sustainability of natural, social and personal systems and the peace and prosperity that human beings tend to seek [11]. The emphasis of sustainability science will gradually shift from issues of natural resources and the environment to how to move toward more fundamental human development [11].

For industry, it is important to bridge between such future scenarios at the global level and long-term R\&D planning at the company level. Komiyama showed how infrastructure for conserving energy and recycling materials can be created by 2050 [12]. Although it is a good example of a technological target indicating the direction of technology development, selecting a path to the goal is an issue for individual research institutes. For instance, Siemens publishes its Pictures of the Future (PoF) periodically, in which future technologies are related to the future society [13].

\subsubsection{R\&D Management}

Because $R \& D$ is a key factor of innovation, it is necessary to manage the $R \& D$ process to meet the characteristics of the $R \& D$ organization and the era. To date, $R \& D$ management has evolved from the 1 st to the 4 th generation as follows [14]:

- The 1st generation of R\&D management is summarized as the unbounded search for scientific breakthroughs in light of researchers' intuition. This generation prevailed until the 1960s;

- The 2nd generation of R\&D management is summarized as project management. In this management, an institution's own technological seeds play an important role. This generation prevailed until the mid-1980s;

- The 3rd generation of R\&D management focuses on market needs-driven R\&D, namely, $R \& D$ associated with corporate strategy [15]. It uses surveys to determine existing customer needs, and targeted technology development to create products and services to fulfill those needs. 3rd-generation R\&D management emphasizes continuous innovation bounded by the wall of experience and the wall of expectations. The latter implies staying within the boundaries of existing products and services. The core processes are explicit customer feedback, corporate strategy, and inventive research in technology. Technology portfolios [16] and roadmaps attempt to extrapolate the future performance, and they constitute the product development activities. Stage gate management is also applied [17]. The 3rd generation has prevailed since the mid-1980s, and has been the main stream because it is easy to establish systematic management; 
- The 4th generation of $R \& D$ management is summarized as discontinuous innovation by co-evolution with stakeholders to overcome the two walls in the 3rd generation. One emphasis of this generation is discovery of potential market needs. Creating the conditions for implementation of 4th-generation R\&D management requires significant changes throughout the organization. This generation has been introduced since 2000 .

Although R\&D management has been evolving in this way, little research has been published on integration of environmental sustainability into R\&D management. Roome pointed out the need for not only technical methods but also for new learning structures within organizations to transform environmental considerations into R\&D practice, but he did not refer to any concrete examples [18]. Foster and Green investigated how green issues are influencing the process of R\&D through interviews with R\&D managers and other managers in British companies [19]. They found there are different green innovation frameworks according to the information flows relating green issues. For example, the sources of the signals are customer, regulation and corporate policy. However, it is pointed out that researchers are not in a strong position to act on such signals in a proactive fashion.

In the National Institute of Advanced Industrial Science and Technology (AIST), it has been mandatory since 2001 for all research themes submitted to AIST to be evaluated in terms of sustainability by the researchers themselves [20]. For this purpose, metrics for determining the sustainability of research themes are emphasized. For example, consideration of metrics of "minimal manufacturing," i.e., creation of maximum functionality by minimum inputs of energy and other resources in manufacturing, is one approach to such metrics. The example of AIST suggests that each research field might have its own metrics or evaluation pattern for sustainability.

\subsubsection{Eco-Innovation and Eco-Value}

Innovation is roughly categorized into process innovation or value innovation. The former is for improving efficiency or optimizing cost, the latter is for creating new value-added or new function. For example, in product design, eco-improvement [21] and eco-innovation [22,23] design correspond to those categories, respectively. Stevels and Pascual defined eco-value of a product as the ratio between the cost of ownership of a product for the user (numerator) and the environmental load of the product over its life cycle (denominator) [24]. Although they emphasized the difference between functional eco-efficiency and eco-value approaches, their definition of eco-value can be regarded as ecoefficiency in a broad sense [25]. The eco-value of Stevels reflects the assumption that consumers will pay extra for greater eco-efficiency, because it is preferable from a business perspective and the monetary rebound effect would be reduced [24]. Because R\&D is a key to value innovation, eco-value is also an important factor when attempting to take the environmental aspect of an $R \& D$ theme into account.

\subsubsection{Environmental Management and Evaluation for R\&D}

An operational procedure of an enterprise's environmental management system (EMS) is defined by ISO14001 [26]. The plan, do, check, action (PDCA) cycle in EMS is an appropriate learning structure for an organization. The key to the PDCA learning cycle is to set adequate metrics. However, 
EMS of R\&D is more difficult than that of manufacturing or office work, because adequate metrics and an evaluation methodology for R\&D themes have not been established yet. Therefore evaluation methods for R\&D themes from an environmental viewpoint need to be developed. We introduced our first checklist for R\&D themes in 1998 [27]. It dealt with the direct environmental impacts, both positive and negative, of the use of technology. However, indirect effects of technology, such as work efficiency improvement by the application of information and communication technology (ICT), were not assessed explicitly.

Many quantitative environmental evaluation methods have also been developed for products. For instance, environmental life cycle assessment (LCA) [28] and evaluation of ICT solutions [29] are applicable to products and services. However, full LCA is difficult to apply because of the lack of detailed product life cycle information at the R\&D stage. A streamlining approach [30] is useful in such cases. Resource supply risks have recently become a focus of attention in the context of rising prices of base metals and rare earth metals. As an indicator for material saving, Total Material Requirement (TMR) [31] is proposed. Estimation of chemical risks is also important. Therefore, combining LCA and risk analysis has been discussed [32]. A toxic potential indicator (TPI) [33] is easy to use but focuses on only hazard, whereas chemical risk has to be considered in terms of both hazard and exposure. Although it is particularly important to systematize an evaluation methodology using these qualitative and quantitative metrics for $R \& D$ management, no such systematized methodology has been proposed yet.

\subsection{Approach of this Study}

To overcome the issues mentioned in Section 2.1, our interdisciplinary approach is based on the following concepts:

- To regard long-term future research for sustainability based on rigorous science and engineering as the basis of RDMOET;

- To build a learning structure by using the eco-value evaluation of R\&D;

- To be consistent with the 3 rd generation of R\&D management for ease of introduction.

In this paper, "future research for sustainability" is defined as any exploration of what may happen and what may be desirable in the field of sustainability. As mentioned in Subsection 2.1.1, sustainability is a broad concept encompassing the search for balance among environmental, economic, and societal challenges and opportunities [11]. Although the environmental aspect is the principal focus of sustainability research, future societal and economic changes, such as sustainable consumption, dematerialization and de-growth, are also considered in RDMOET for eco-innovation, because innovation is achieved not only by technological breakthroughs but also by changes in the way technology is used in society. Unfeasible future targets and scenarios devoid of engineering rigor mislead R\&D. In this paper, it is considered that feasible long-term targets and scenarios grounded in sustainability research should be established based on rigorous science and engineering.

An essential driving force of R\&D is the motivation of individual researchers, such as the desire to apply a new principle to a new device. Many researchers are inclined to emphasize the functionality of their R\&D theme but not the risks involved. Generally, they are not motivated to evaluate their themes 
from environmental perspectives. Moreover, because researchers may not recognize their R\&D technologies are eco-technologies, the opportunity to identify application fields may be missed. They tend to presume their work is superior to other work in the same research field; moreover, sometimes they are dismissive of other work. Thus, it is useful to evaluate their research work objectively. Clearly, since overmanagement or excessive interposition in research might disturb innovation, research themes should be managed carefully. This means RDMOET should be consistent with the existing R\&D management methods, such as 3rd-generation R\&D management [15], portfolio management [16] and stage gate [17].

\section{RDMOET Framework}

\subsection{Overall Structure of RDMOET}

Figure 2 shows a framework of RDMOET consisting of four major processes that are not necessarily executed sequentially and strictly but rather simultaneously and flexibly. Processes (a) and (d) are unique to RDMOET, whereas methods utilized in processes (b) and (c) are similar to those of conventional 3rd-generation R\&D management. The processes are as follows:

(a) Future research for sustainability: The crucial basis of RDMOET is future research based on rigorous science and engineering. In this process, forecasting and backcasting scenarios are examined for a broad spectrum of energy, natural resource, social, economic, and other environmental problems. The major outputs of the process are an R\&D vision and feasible scenarios for realizing environmental sustainability;

(b) Making an original eco-theme portfolio and roadmap: Based on the results of future research, an original eco-theme portfolio and roadmap are made, considering the characteristics of the company. Unlike in the case of a typical R\&D portfolio and roadmap, the eco-themes have to be consistent with long-term sustainability;

(c) Gap analysis and implementation of new eco-themes: If a gap between the eco-theme portfolio and roadmap and the current R\&D portfolio and roadmap is found, an attempt is made to implement eco-themes in R\&D activities;

(d) Eco-value evaluation of R\&D themes: This process is a key to organizational learning for eco-value innovation. Here, eco-value of technology is defined as the advantage of environmental competitiveness in the market. In other words, eco-value is recognized by benchmarking the target technology against competitive technologies. This evaluation result is reflected in the existing R\&D management, such as enhancement or cut-off of themes. 
Figure 2. A framework of RDMOET.

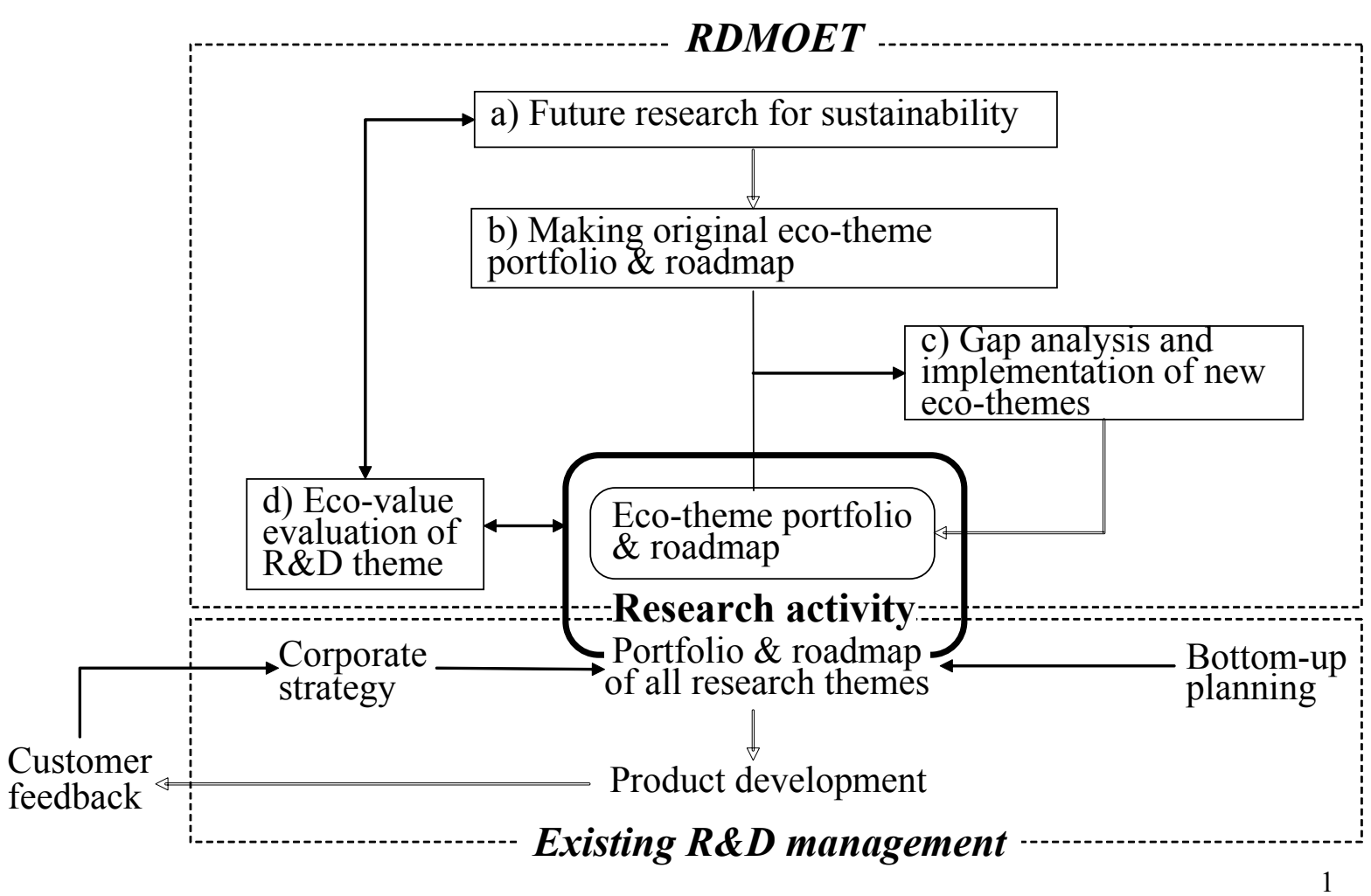

\subsection{Eco-Value Evaluation of $R \& D$ Themes}

Process (d) in Figure 2 is shown in detail in Figure 3.

Figure 3. Eco-value evaluation process within RDMOET.

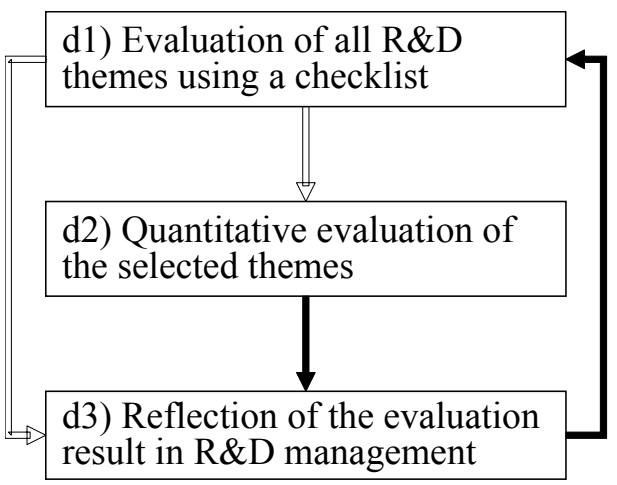

The processes shown in Figure 3 are explained as follows:

(d1) Evaluation of all R\&D themes using a checklist: In Step 1, a checklist approach is applied to all R\&D themes at regular intervals. A checklist should be easy for researchers to use. An eco-value checklist of R\&D themes was developed by researchers. This checklist approach is based on benchmarking against the current best practice, and the checklist covers energy saving, low carbon emission, material saving, reuse/recycle, chemical risk reduction, etc. The indirect effects of the target technology are assessed for each viewpoint explicitly. The evaluation of indirect effects is useful for enhancing the positive effects of technology; 
(d2) Quantitative evaluation of the selected themes: A target theme to be evaluated is selected based on the result of the above-mentioned checklist. R\&D management may also strategically select evaluation themes for promotion. The first point is that an evaluation team is organized within a laboratory and an experts group is organized to perform eco-value evaluation of each theme. The second point is to identify a reasonable scenario for emerging eco-technology and explore its implications based on benchmarking against the best practice or alternative technology. Suitable evaluation metrics and system boundary are set corresponding to characteristics of the $R \& D$ theme. For instance, power generation technology is evaluated by energy profit ratio (EPR) or energy payback time (EPT). Low-carbon technology is evaluated by the amount of life cycle $\mathrm{CO}_{2}\left(\mathrm{LCCO}_{2}\right)$ emission. Energy-saving technology is evaluated by energy efficiency or the amount of energy consumption. Mineral-resource-saving technology is evaluated by TMR. Chemical risk or hazard of materials is evaluated by TPI. For ease of evaluation and reflection in R\&D, the more focused the evaluation, the more accurate the conclusion derived even though there is a risk of lack of comprehensiveness;

(d3) Reflection of the evaluation result in R\&D management: An evaluation result is reviewed and shared among an evaluation team, R\&D management, eco-technology management, and an $R \& D$ board. When a new advantage or disadvantage of an $R \& D$ theme is found, the $R \& D$ approach is changed as necessary.

\section{Practical Examples}

In this section, examples of future research for sustainability and eco-value evaluation of R\&D themes are shown, because they are new processes compared with conventional R\&D management.

\subsection{Future Research for Sustainability}

In this subsection, an example of futures research concerning electricity demand and supply is explained. With regard to climate change, which is the foremost global environmental issue, long-term targets for reducing greenhouse gas (GHG) emissions have been discussed [8]. Since GHG reduction targets strongly depend on characteristics of countries, such as their policies and the nature of their economies, they are not necessarily adequate for other countries' situations. A scientific approach is necessary. Komiyama estimated the future target for sustainable technology development in Vision 2050 based on three preconditions [12], namely:

- Developing countries are guaranteed the right to modernize;

- Vision 2050 cannot be based on unrealistic expectations of people making radical changes in their lifestyles;

- We will still be dependent on fossil fuels in 2050 .

As an estimation result, he concluded there should be three main targets of Vision 2050 as follows:

- A three-fold increase in energy use efficiency;

- A two-fold increase in use of renewable energy;

- Conversion to a system of material recycling. 
In that estimation, however, the detail of the calculation is not clarified. For example, considerations of electrification and progress of ICT are inadequate. Moreover, the uncertainty of some important parameters, such as installation of non-fossil fuel power and energy intensity of developing countries, is not considered. We have tried to estimate the target values of energy-use efficiency and low-carbon power generation for halving GHG emissions compared with the current level. The preconditions of our estimation are as follows:

- Social and economic:

1. The estimation of population growth is assumed. Namely, the world's population will be 9.2 billion in 2050 ;

2. The affluence of $70 \%$ of the world's population will be the same as that of the current developed countries.

- Technological:

1. The IEA Blue Map scenario is a basis for halving GHG emissions compared with the current level;

2. Progress of electrification. Namely, all energy supply for automobiles, hot-water supply and cooking will be electricity. The problem of water shortages in developing countries will be solved by electric seawater desalination technology;

3. Progress and diffusion of ICT is taken into account based on the situation in Japan [34].

First, we analyzed energy consumption per capita in the countries and regions of the world, and estimated the effect of electrification (Figure 4). In the analysis and estimation, progress of ICT [34] and countermeasures for water stress in developing countries [35] were taken into account.

Figure 4. Estimation of electricity consumption per capita 2050.

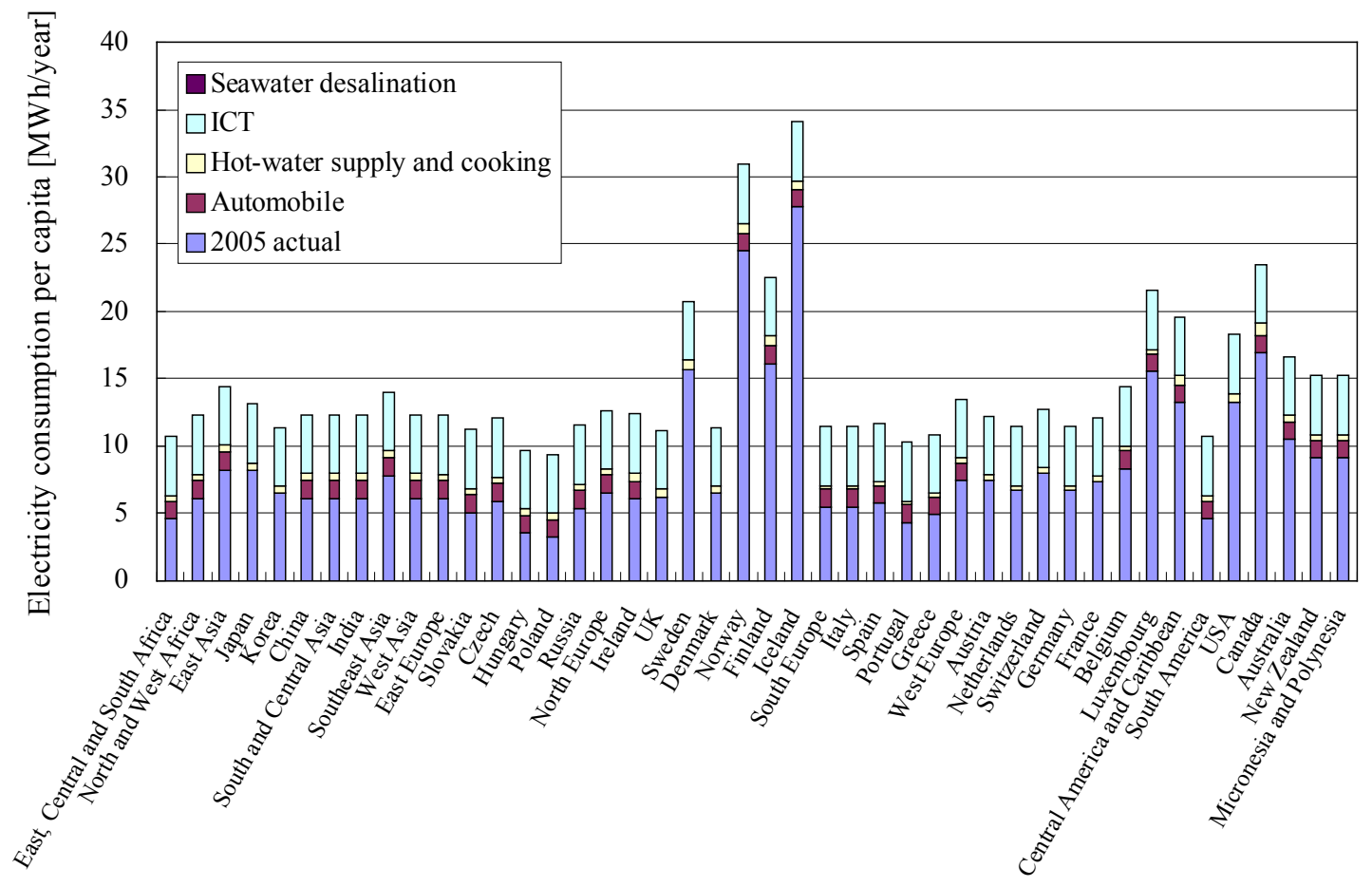


In the IEA Blue Map scenario [7], it is estimated that global electricity generation will be 42,340TWh in 2050. In the Blue Map scenario, the ratio of electricity generated by non-fossil fuel in 2050 is assumed to be $70 \%$ of the total supply, whereas it was $33 \%$ in 2005 . Figure 5 illustrates the configuration of electricity generation in the Blue Map scenario.

Figure 5. Configuration of electricity generation in the Blue Map scenario [7].

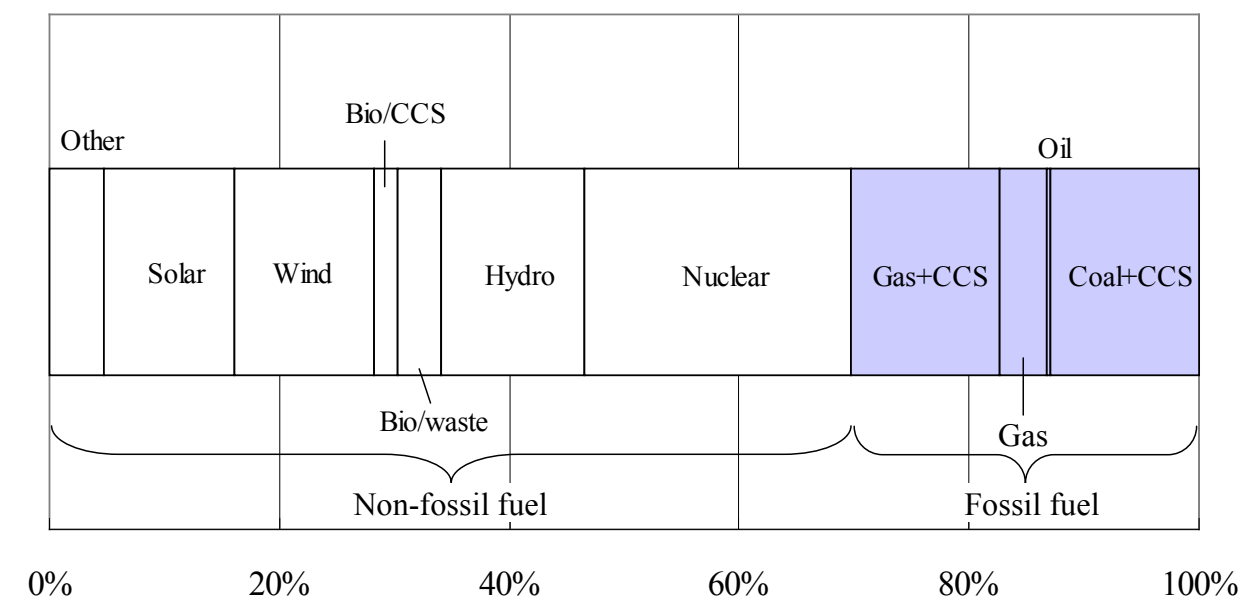

Electricity production ratio in 2050

Next, the estimated electricity consumption per capita is shown in Figure 6. Here, the "2050 Sustainable Electrification" scenario is derived to satisfy the previous preconditions. This means electricity consumption must be reduced by $60 \%$ compared with the 2050 Electrification BAU scenario for GHG stabilization. In other words, a two-and-a-half-fold increase in the efficiency of electricity use is necessary by 2050 . Because loss of electricity during transmission and distribution (T\&D) is ignored in the estimation, we have to consider T\&D loss. As a result, almost the same target of energy saving is derived as in Vision 2050 [12] from slightly different preconditions.

Figure 6. 2050 target of electricity-saving technology.

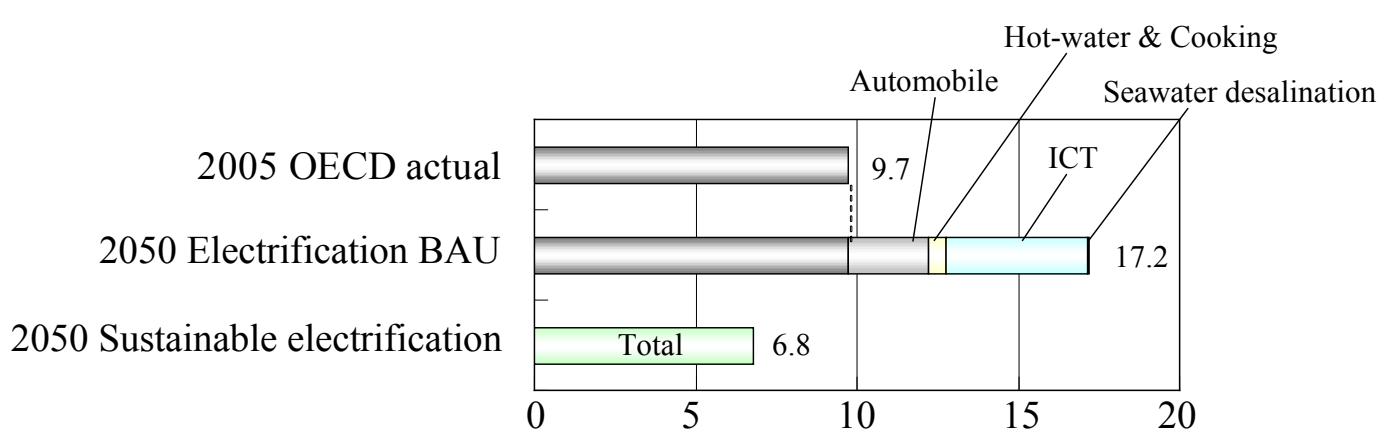

Electricity consumption per capita [MWh/year]

Finally, uncertainty is considered (Figure 7). If the ratio of electricity generated with non-fossil fuel is $60 \%$, the target value of energy saving increases to $90 \%$. Also, modernization in developing countries, namely social and economic precondition 2, affects the target area. In any event, the estimation result shows that a challenging target is necessary for both the demand-side energy saving and the non-fossil fuel electricity generation. 
Figure 7. Targets of energy-saving ratio and non-fossil-fuel ratio in electricity generation.

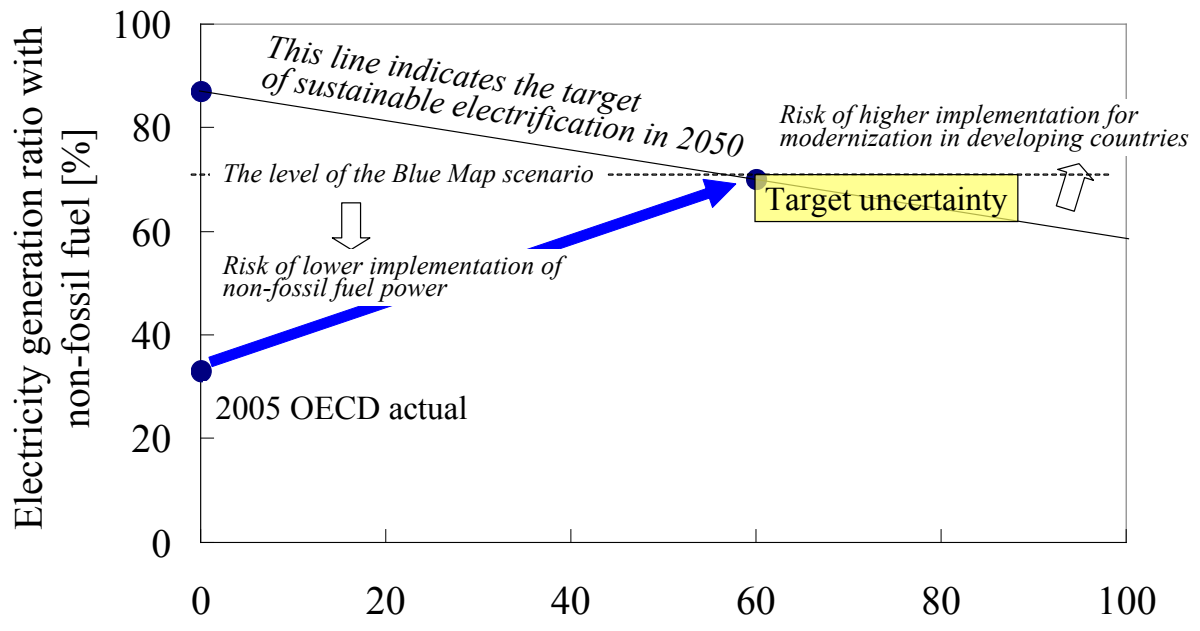

Energy-saving ratio compared with FY2050 [\%]

In addition to the issue of climate change mitigation, some important sustainability issues are studied, such as mineral resource supply, chemical hazard and biodiversity, as themes for future research. We believe that doing such future research and sharing the results will be useful, because we can attain a relatively realistic grasp of the future situation when developing ideas for eco-themes.

\subsection{Eco-Value Evaluation of $R \& D$ Themes}

We assume that the difference of environmental performance could be converted to a monetary value through competition. Since it is difficult to estimate product prices derived from the target technology in the R\&D process, we focus on environmental performance. A basic concept is not complete LCA [28] but benchmarking using adequate metrics, such as a streamlining approach [30], indicator for material saving TMR [31], indicator for toxicity TPI [33] and evaluation of ICT solutions [29]. At the Corporate $R \& D$ Center of Toshiba Corporation, $R \& D$ activities cover a wide spectrum from nanotechnology to ICT, and from basic to applied research. Thus, the evaluation methodology has to cover these various fields.

\subsubsection{Checklist Evaluation}

Based on [27], a checklist for all R\&D themes has been revised that includes not only direct effects but also indirect effects. The evaluation items are shown in Table 1. A responsible researcher evaluates his own research theme compared with competitors' technologies. 
Table 1. Examples of evaluation items of the checklist for all R\&D themes.

\begin{tabular}{|c|c|c|c|c|c|c|c|c|}
\hline $\begin{array}{l}\text { Evaluation } \\
\text { category }\end{array}$ & Evaluation item & \multicolumn{7}{|c|}{ Check mark based on comparing with competitor's technology } \\
\hline \multirow{12}{*}{$\begin{array}{l}\text { 1. Energy saving } \\
\text { and low } \\
\text { carbonization }\end{array}$} & \multirow{4}{*}{$\begin{array}{l}\text { a) Energy consumption in } \\
\text { manufacturing }\end{array}$} & \multicolumn{2}{|c|}{ Increase } & \multirow{2}{*}{ Same } & \multicolumn{2}{|c|}{ Decrease } & \multirow{2}{*}{ Unknown } & \multirow{2}{*}{$\begin{array}{c}\text { No } \\
\text { correspondence }\end{array}$} \\
\hline & & Confirm & Intuition & & Intuition & Confirm & & \\
\hline & & & & & & & & \\
\hline & & \multicolumn{7}{|l|}{ Reason: } \\
\hline & \multirow{4}{*}{ b) Energy consumption in use } & \multicolumn{2}{|c|}{ Increase } & \multirow{2}{*}{ Same } & \multicolumn{2}{|c|}{ Decrease } & \multirow{2}{*}{ Unknown } & \multirow{2}{*}{$\begin{array}{c}\text { No } \\
\text { correspondence }\end{array}$} \\
\hline & & Confirm & Intuition & & Intuition & Confirm & & \\
\hline & & & & & & & & \\
\hline & & \multicolumn{7}{|l|}{ Reason: } \\
\hline & \multirow{4}{*}{$\begin{array}{l}\text { c) Indirect reduction of energy } \\
\text { consumption }\end{array}$} & \multicolumn{2}{|c|}{ Negative effect } & \multirow{2}{*}{ Same } & \multicolumn{2}{|c|}{ Positive effect } & \multirow{2}{*}{ Unknown } & \multirow{2}{*}{$\begin{array}{c}\text { No } \\
\text { correspondence }\end{array}$} \\
\hline & & Confirm & Intuition & & Intuition & Confirm & & \\
\hline & & & & & & & & \\
\hline & & \multicolumn{7}{|l|}{ Reason: } \\
\hline \multirow{14}{*}{$\begin{array}{l}\text { 2. Resource } \\
\text { saving }\end{array}$} & \multirow{3}{*}{ a) The amount of resource use } & & & Som & Dec & ase & Thlons & No \\
\hline & & Confirm & Intuition & Same & Intuition & Confirm & Unknown & correspondence \\
\hline & & Reason: & & & & & & \\
\hline & & & & & Dec & & & \\
\hline & b) The amount of rare mineral & Confirm & Intuition & Same & Intuition & Confirm & Unknown & correspondence \\
\hline & use & & & & & & & \\
\hline & & & & & Reaso & & & \\
\hline & & Negat & effect & Somot & Positi & effect & Unl known & \\
\hline & c) Indirect reduction of resource & Confirm & Intuition & Same & Intuition & Confirm & Unknown & correspondence \\
\hline & use & Peasen. & & & & & & \\
\hline & & & & & Len & hen & & \\
\hline & d) Derductif & Confirm & Intuition & Same & Intuition & Confirm & Unknown & correspondence \\
\hline & d) Product life & & & & & & & \\
\hline & & Reason: & & & & & & \\
\hline & & & cult & Same & & & Untroun & No \\
\hline & Peuse or recycle & Confirm & Intuition & Same & Intuition & Confirm & Unknown & correspondence \\
\hline & 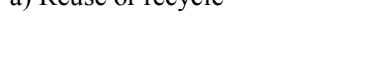 & Reason: & & & & & & \\
\hline $\begin{array}{l}\text {. Kesource } \\
\text { circulation }\end{array}$ & & Negat & effect & & Positi & effect & & No \\
\hline & b) Dromotion of roucon morel & Confirm & Intuition & Same & Intuition & Confirm & Unknown & correspondence \\
\hline & D) Promotion or reuse or recycie & & & & & & & \\
\hline & & Reason: & & & & & & \\
\hline & a) Materials subject to & & Contain & & & Not contain & & $\begin{array}{c}\text { No } \\
\text { correspondence }\end{array}$ \\
\hline & legislation & Reason: & & & & & & \\
\hline material & & Negat & effect & Sompl & Positi & effect & Untonaun & No \\
\hline & b) Indirect reduction of harmful & Confirm & Intuition & Same & Intuition & Confirm & Unknown & correspondence \\
\hline & materials use & Reason: & & & & & & \\
\hline
\end{tabular}

All R\&D themes are categorized into four types by grouping rules based on the checklist result. The four types are (a) eco-theme with quantitative evidence; (b) qualitative eco-theme; (c) gray theme; and (d) non-eco-theme. The results of themes of type (d) are reflected in R\&D management such as stage gate judgment. Figure 8 shows time series data of a grouping result of R\&D themes in different research fields using the checklist method. Here, field $\mathrm{I}$ is fundamental or mature mechanical technology, field II is ICT, field III is electronic devices, and field IV is advanced materials. It shows that the configuration of field I changed little during three years. The ratio of type (b) theme is large, because fundamental mechanical technology is not for specific purpose in many cases. In field II, type (a) and (b) increase year by year, because the indirect eco-effects are recognized. However, quantitative eco-value is unknown in many cases because quantifying eco-value of ICT is difficult in 
general. On the other hand, it is easy to quantify the eco-value in field IV. Here, the ratio of type (a) eco-theme decreases in field III because the portfolio of R\&D themes in field III has hardly changed during three years. In this way, R\&D managers can recognize the current status of the fields for which they are responsible within the overall view.

Figure 8. A grouping result of R\&D themes.

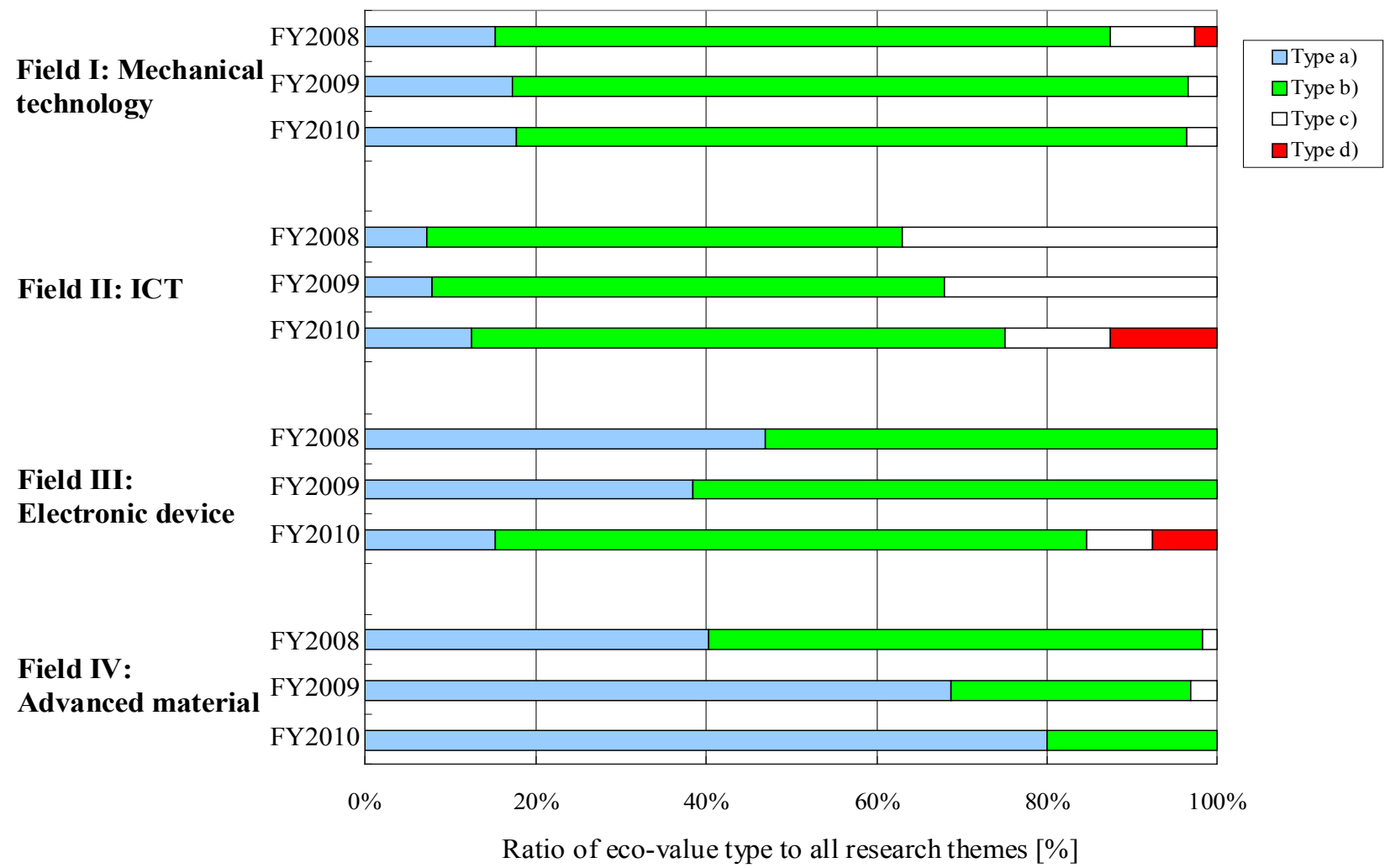

By combining the category and stage gate information of R\&D themes, portfolio analysis for eco-technology is examined. Table 2 shows a frame of an expected relation matrix using the types and stages of R\&D themes. Actual information of eco-themes is plotted in the matrix. Based on comparison between an expected matrix and a real one, the current status is confirmed. For example, if there are many gray themes from an environmental aspect in developing and testing stages, then they are to be confirmed by eco-value evaluation.

Table 2. An expected relation matrix of eco-themes.

\begin{tabular}{|c|c|c|c|c|c|}
\hline & \multicolumn{4}{|c|}{ Type of R\&D theme } \\
\hline & & $\begin{array}{l}\text { Type a): } \\
\text { eco-theme with } \\
\text { quantitative } \\
\text { evidence }\end{array}$ & $\begin{array}{l}\text { Type b): } \\
\text { qualitative } \\
\text { eco-theme }\end{array}$ & $\begin{array}{l}\text { Type c): } \\
\text { gray theme }\end{array}$ & $\begin{array}{l}\text { Type d): } \\
\text { non eco- } \\
\text { theme }\end{array}$ \\
\hline \multirow{3}{*}{ 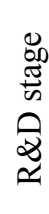 } & $\begin{array}{l}\text { Idea discovery \& concept } \\
\text { development }\end{array}$ & & & High & \\
\hline & Feasibility study & & High & & \\
\hline & Development \& testing & High & & & \\
\hline
\end{tabular}

"High" means the ratio of eco-themes is relatively high at each stage. 


\subsubsection{Quantitative Evaluation}

For various fields, ICT has great potential to mitigate energy consumption by increasing process efficiency [34]. However, it is difficult to quantify when the target process for application of the ICT solution depends on thought processes. For ICT evaluation [29], process modeling is a key. Generally, a problem-solving cycle consists of awareness of the problem, suggestion, development, evaluation, and decision processes [36]. The information retrieval process on which we focus here typically involves awareness of the problem and suggestion processes.

In this subsection, an example of the energy-saving-potential evaluation of retrieval technology using eXtensible Markup Language Database (XML-DB) in the case of a patent retrieval system is shown [37,38]. The operation process of patent retrieval is modeled in Figure 9. In this case, XML-DB and relational DB (RDB) retrieval systems are compared. The former enable full text retrieval with free keyword, but the latter only enable attribute retrieval with fixed keyword. Based on actual data log and investigation of related divisions, expended time from inputting free or fixed keywords to downloading data is set as one hour, and expended time for identification of related patents is one minute per subject. Numbers of selected patents by XML-DB and RDB systems are estimated as 150 and 2,775 , respectively.

A patent retrieval system with free keyword using XML-DB saves $93 \%$ of carbon dioxide $\left(\mathrm{CO}_{2}\right)$ compared with that with fixed keyword using RDB (Figure 10). In this case, indirect energy consumption by office utilities, such as lighting and air conditioning, is much larger than direct energy consumption by ICT equipment.

Figure 9. Process model of patent searching.

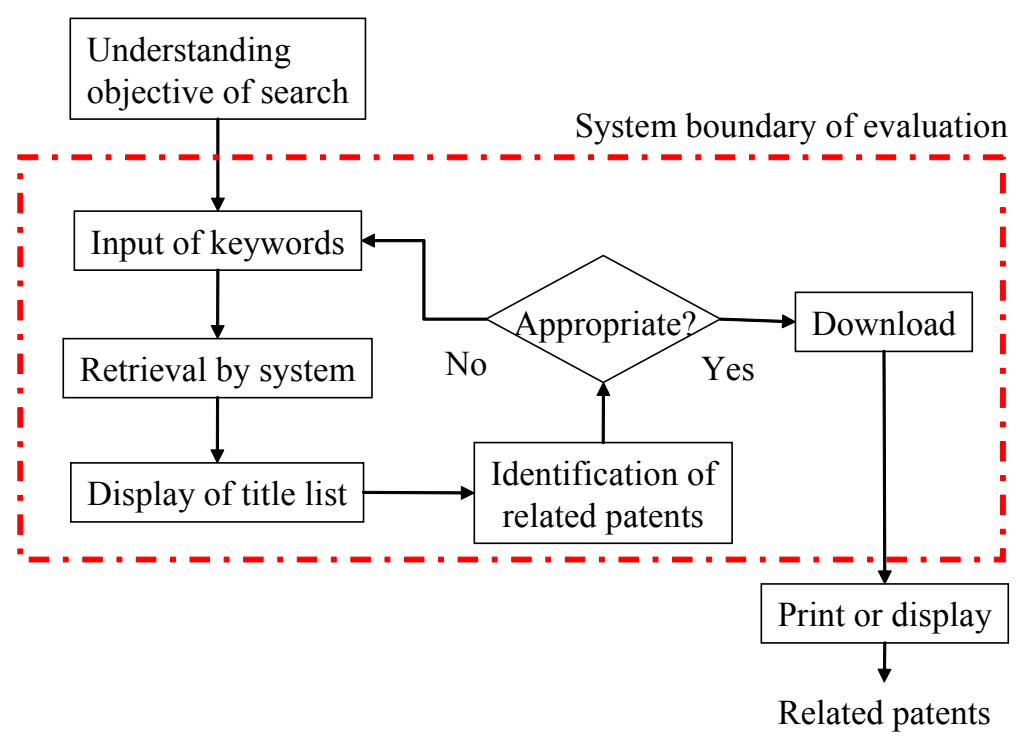


Figure 10. Benchmarking result using $\mathrm{CO}_{2}$ emissions.

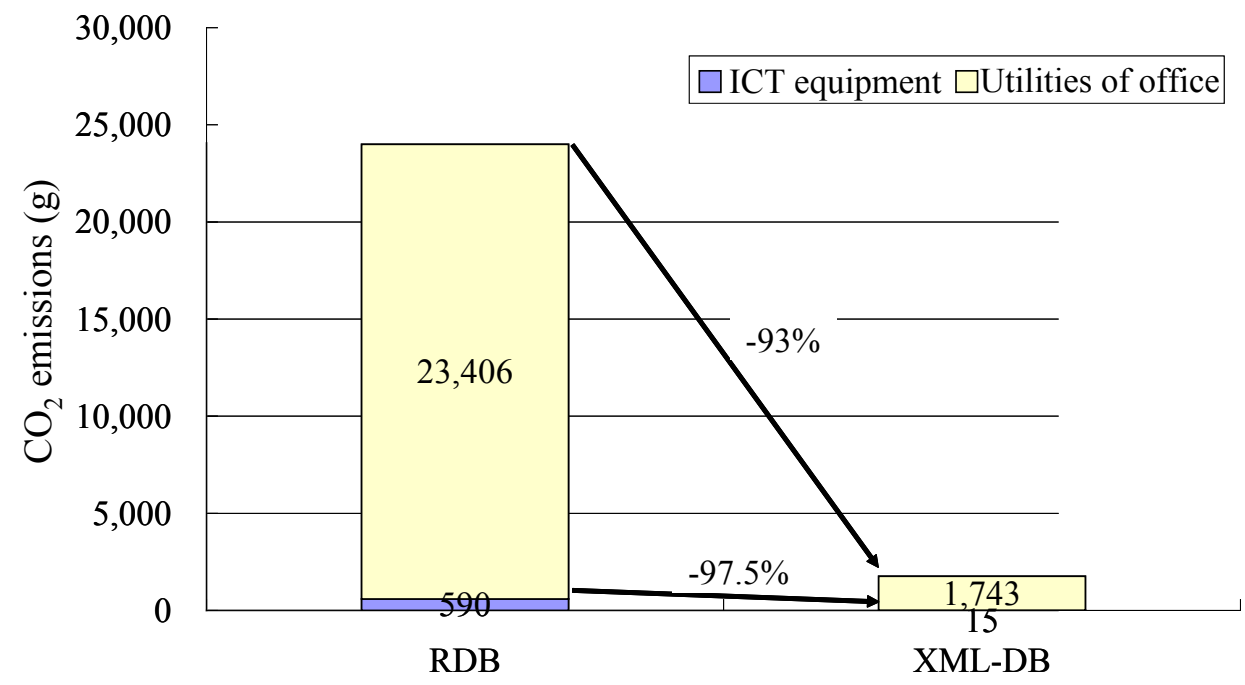

\section{Discussion}

\subsection{Comparison with Reference Management Theories}

We consider 3rd-generation R\&D management [15] and operational procedures of an enterprise's EMS [26] to be important reference management theories comparable with RDMOET, given that 3rd-generation R\&D management remains a theory widely applied in industry and EMS is the basis of the environmental activities of enterprises. In general, the two management systems are independent of each other. One major reason is that an EMS process is virtually routine work as a PDCA cycle, whereas an R\&D management process is agile because it is linked to changes in the business environment. Therefore, it is difficult to integrate these two management processes. Another reason is that the divisions responsible for the two management processes are different. For example, R\&D management is usually promoted by the research planning division, whereas EMS is usually promoted by the environmental division.

In contrast, RDMOET can link 3rd-generation R\&D management and EMS. The eco-value evaluation process of RDMOET is regarded as periodic, virtually routine work (Figure 3), and this evaluation process can be managed as a PDCA cycle of EMS. For instance, planning and execution of $\mathrm{R} \& \mathrm{D}$ themes is done by the research division, the check process using eco-value evaluation is promoted by eco-technology management, and action is taken by the R\&D board. Furthermore, processes (b) and (c) in Figure 2 are agile and synchronized with 3rd-generation R\&D management. As a result, the eco-theme portfolio and roadmap reflecting the eco-value evaluation results are always shared by the R\&D board, and eco-technology is recognized in R\&D management. However, decisionmaking cannot be executed systematically when a conflict arises between long-term and short-term requirements. In such a case, the enterprise's philosophy or policy is reflected in the decision.

In 3rd-generation R\&D management, the focus is on actualized market needs because R\&D is tightly linked to a business plan, whereas consideration of potential needs is weak. The EMS procedure also cannot treat potential environmental needs, only actualized environmental issues. In 
contrast, process (a) in Figure 2 plays an important role in the discovery of potential needs for eco-innovation as a basis of RDMOET.

\subsection{Advantages, Disadvantages, Lessons and Limitations of the Proposed Framework}

In this sub-section, the advantages, the disadvantages, the lessons and the limitations of the proposed framework are summarized.

There are three advantages. The 1st advantage is that it provides a systematic way to bridge between long-term environmental sustainability and medium- or short-term research work plans. Since the proposed framework is familiar to those who have experience of 3rd-generation R\&D management and EMS, it is easy to put it into practice.

The 2nd advantage is that the RDMOET framework realizes data-driven management of eco-technology through accumulation of eco-value evaluation results. Eco-value of research themes can be categorized into patterns in research fields. These eco-value patterns help overcome the valley of death that must be traversed in the transition from R\&D to the market by viewing a research theme from a different perspective, such as in terms of electricity saving or less material use. This is an organizational learning effect at the management level.

The 3rd advantage is the change in the mindset of individual researchers brought about by their evaluation of their own research themes, with technical support. We have observed the increase of environmental awareness in both R\&D management and among researchers brought about by the proposed approach. In other words, we recognize that the eco-value evaluation promotes organizational learning that contributes to evolution of the R\&D process. However, it is difficult to quantify the effect of the organizational learning. That is a subject for future work.

The disadvantage of the framework is there is a risk of losing the diversity of original ideas if operation of the framework is excessively strictly. For instance, even though a negative result is derived from an eco-value evaluation, care must be exercised so as not to reduce researchers' motivation. With regard to application and operation of the framework, one must proceed with care. An important lesson from our practice is that abolishing research themes should be avoided to ensure sufficient diversity of research themes if possible. Rather, focusing on monitoring and correcting the direction of research themes with potential eco-value drives change of a research organization toward more active eco-innovation.

Our framework has three limitations. The 1st limitation is that it is not general but specifically designed for the Corporate R\&D Center of Toshiba Corporation. Therefore, the methodology presented here should be modified if it is applied to other research institutes. For example, the proposed RDMOET framework has to be modified for an open innovation environment such as the 4th-generation $\mathrm{R} \& \mathrm{D}$ management framework. $\mathrm{R} \& \mathrm{D}$ management is also highly dependent on know-how and organizational culture. Although their explicit representation is important for improving the proposed framework by making it more generally applicable, it is inherently difficult to share practice examples and organizational cultures.

The 2nd limitation is that the proposed framework cannot be executed without managerial vision and strong leadership to promote RDMOET. For instance, the CEO's commitment is a powerful factor and Environmental Vision 2050 is shared throughout Toshiba Group [39], providing a managerial 
foundation for promoting RDMOET. Additionally, RDMOET is promoted throughout the Corporate R\&D Center of Toshiba Corporation by a department established for that purpose. The department is the linchpin of RDMOET operation and its existence attests to a powerful commitment.

The 3rd limitation concerns future research and eco-value evaluation. Future research methodology involves many quantitative/qualitative, normative/exploratory models and methods [6]. Since a single research organization cannot conduct future research covering all fields, a methodology is required in order to compare or integrate various future scenarios [40,41]. For evaluation of new technology, it has been pointed out that eco-efficiency at the micro level is not necessarily consistent with sustainability at the macro level [42]. Therefore, it is important to pay attention to the estimation of the macro effect of the target eco-technology. For instance, the rebound effect, which is one of the side effects of new technology, has recently become a focus of interest [43], and we have developed an indirect rebound effect estimation method [44]. It is necessary to systematize the relationship between evaluations at the micro and macro levels theoretically.

\section{Conclusion}

In this paper, we proposed a framework of RDMOET consisting of four simultaneous and flexible processes, namely, (1) future research for sustainability; (2) making an original eco-theme portfolio and roadmap; (3) gap analysis and implementation of new eco-themes; (4) eco-value evaluation of R\&D themes. Unlike in conventional R\&D management, the future research for sustainability and the eco-value evaluation are key processes of RDMOET. Although both processes have a scientific basis, the eco-value evaluation needs a more organizational approach. The usefulness of the proposed framework is proved through practice at the Corporate R\&D Center of Toshiba Corporation during four years. Subjects for future work are as follows:

- Modify to ensure conformance to the 4th-generation of R\&D management, which emphasizes open innovation;

- Quantify the organizational learning effect by RDMOET;

- Develop an integrated future scenario methodology and eco-value evaluation bridging between the micro-level and the macro-level.

\section{Acknowledgements}

We would like to thank K. Essaki, Y. Hondo, M. Inaba, S. Kaji, Y. Kobayashi, F. Kondo, T. Kono, K. Kubota, S. Mikoshiba, S. Murai, T. Ono, Y. Shobatake, N. Shuto, M. Takenaka and H. Watando of Toshiba Corporation for contributing to the establishment of the RDMOET framework.

\section{References}

1. Harjula, T.; Rapoza, B.; Knight, W.; Boothroyd, G. Design for disassembly and the environment. CIRP Ann. - Manuf. Technol. 1996, 45, 109-114.

2. Kobayashi, H. Strategic evolution of Eco-products: A product life cycle planning methodology. Res. Eng. Des. 2005, 16, 1-16. 
3. Stevels, A. Adventures in EcoDesign of Electronic Products; Delft University of Technology, Delft, The Netherlands, 2008.

4. Middendorf, A.; Reichl, H.; Griese, H. Lifetime Estimation for Wire Bond Interconnections using Life-Cycle-Information Modules with Implemented Models. In Proceedings of Fourth International Symposium on Environmentally Conscious Design and Inverse Manufacturing 2005, Eco Design 2005, Tokyo, Japan, 12-14 December 2005; pp. 614-619.

5. Feldhusen, J.; Bungert, F. PLM Pattern Language: An Integrating Theory of Archetypal Engineering Solutions. In Proceedings of the 14th CIRP Conference on Life Cycle Engineering, Tokyo, Japan, 11-13 June 2007; pp. 125-130.

6. Glenn, J., Gordon, T., Eds.; Futures Research Methodology V3.0; The Millennium Project, 2010.

7. International Energy Agency (IEA). Energy Technology Perspectives 2008; IEA: Paris, France, 2008 .

8. Intergovernmental Panel on Climate Change (IPCC). Fourth Assessment Report: Climate Change 2007; Cambridge University Press: Cambridge, UK, 2007.

9. Raskin, P.; Electris, C.; Rosen, R. The century ahead: Searching for sustainability. Sustainability 2010, 2, 2626-2651.

10. Kim, J.; Oki, T. Visioneering: An essential framework in sustainability science. Sustainability Sci. 2011, 6, 247-251.

11. Komiyama, H., Takeuchi, K., Shiroyama, H., Mino, T., Eds.; Sustainability Science: A Multidisciplinary Approach; United Nations University Press: Tokyo, Japan, 2011.

12. Komiyama, H.; Kraines, S. Vision 2050: Roadmap for a Sustainable Earth; Springer: Berlin, Germany, 2008.

13. Siemens. Picture of the Future. Available online: http://www.siemens.com/innovation/en/ publications/index.htm (accessed on 7 April 2011).

14. Miller, W.; Morris, L. 4th Generation R\&D; Managing Knowledge, Technology, and Innovation; John Wiley \& Sons, Inc.: Hoboken, NJ, USA, 1999.

15. Roussel, P.A.; Saad, K.N.; Erikson, T.J. Third Generation R\&D; Arthur D. Little, Inc.: Harvard Business School Press, Massachusetts, USA, 1991.

16. Mikkaola, J. Portfolio management of R\&D projects: Implications for innovation management. Technovation 2001, 21, 423-435.

17. Uchihira, N. Stage Gate Analysis in Business-Academia Collaborative Project. In Proceedings of the PICMET 05, Portland, OR, USA, 31 July-4 August 2005.

18. Roome, N. Business strategy, R\&D management and environmental imperatives. R\&D Manag. 1994, 24, 65-82.

19. Foster, C.; Green, K. Greening the innovation process. Bus. Strategy Environ. 2000, 9, 287-303.

20. Yoshikawa, H; Fukuda, K; Shiratori, M; Matsumoto, Y. Global warming and role of engineer. $J$. Jpn. Soc. Mech. Eng. 2009, 112, 85-94 (In Japanese).

21. Kobayashi, H. A method of life cycle planning for product Eco-improvement. Int. J. Environ. Conscious Des. Manuf. 2000, 8, 27-37.

22. Kobayashi, H.; Fushiya, N. Life Cycle Planning Methods for Environmentally Conscious Products. In Proceedings of the 1999 IEEE International Symposium on Electronics and the Environment (ISEE'99), Danvers, MA, USA, 11-13 May 1999; pp. 87-91. 
23. Kobayashi, H. A systematic approach to eco-innovative product design based on life cycle planning. Adv. Eng. Inf. 2006, 20, 113-125.

24. Stevels, A. Adventures in EcoDesign of Electronic Products; Delft University of Technology, Delft, The Netherlands, 2008; pp. 29-37.

25. Huppes, G.; Ishikawa, M. A framework for quantified Eco-efficiency analysis. J. Ind. Ecol. 2005, 9, 25-41.

26. International Organization for Standardization (ISO). ISO14001: Environmental Management Systems - Requirements with Guidance for Use; ISO: Geneva, Switzerland, 2004.

27. Shiratori, M.; Saito, M.; Shimada, H. Environmental impact evaluation method for research and development themes. Toshiba Rev. 1998, 53, 65-67 (In Japanese).

28. Wenzel, H.; Hauschild, M.; Alting, L. Environmental Assessment of Products, Volume 1, Chapman \& Hall, London, UK, 1997.

29. Matsuno, Y.; Aoe, T.; Ebata, S.; Hashitani, T.; Ito, Y.; Kobayashi, H.; Miyamoto, S.; Mochizuki, N.; Nishi, S.; Nishi, T.; et al. Measuring Information and Communication Technologies (ICT) Benefits and Environmental Impact. In Proceedings of Fourth International Symposium on Environmentally Conscious Design and Inverse Manufacturing 2005, Eco Design 2005, Tokyo, Japan, 12-14 December 2005; pp. 766-767.

30. Todd, J., Curran, M., Eds.; Streamlined Life-Cycle Assessment: A Final Report from the SETAC North America Streamlined LCA Workgroup, SETAC: Brussels, Belgium, 1999.

31. Harada, K.; Ijima, K.; Katagiri, N.; Okura, T. An approximate estimation of total materials requirement of metals. J. JIM 2001, 65, 564-570 (In Japanese).

32. Shatkin, J. Informing environmental decision making by combining life cycle assessment and risk analysis. J. Ind. Ecol. 2008, 12, 278-281.

33. Middendorf, A.; Nissen, N.; Griese, H.; Müller, J.; Pötter, H.; Reichl, H.; Stobbe, I. EE-Toolbox A Modular Assessment System for the Environmental Optimization of Electronics. In Proceedings of the 2000 IEEE International Symposium on Electronics and the Environment, San Francisco, CA, USA, 8-10 May 2000; pp. 166-171.

34. Ministry of Internal Affairs and Communications. Available online: http://www.soumu.go.jp/main_content/000065258.pdf (in Japanese, accessed on 7 April 2011).

35. Nagai, M.; Iwahashi, H.; Tanaka, K. Application of reverse osmosis sea water desalination technology on service water treatment. Mitsubishi Heavy Ind. Tech. Rev. 2002, 39, 270-273 (In Japanese).

36. Kobayashi, H.; Hongu, A.; Haruki, K.; Doi, S. A Framework of Eco-design Support. In Proceedings of the 1st International Symposium on Environmentally Conscious Design and Inverse Manufacturing (EcoDesign’99), Tokyo, Japan, 13-15 December 1999; pp. 680-684.

37. Maezawa, Y.; Kobayashi, Y.; Hattori, M.; Kobayashi, H. Estimation of $\mathrm{CO}_{2}$ Reduction with Efficient Business Process using XML-DB. In Proceedings of the 28th Ann. Meeting JSER, 2009; Paper no. 4-2 (In Japanese).

38. Tanigawa, H.; Hattori, M.; Matsui, K.; Sato, M. TX1 XML database realizing high-speed searches in large-scale environments. Toshiba Rev. 2005, 60, 71-75 (In Japanese).

39. Toshiba Environmental Vision 2050. Available online: http://www.toshiba.co.jp/env/en/ management/vision2050.htm (accessed on 7 April 2011). 
40. Umeda, Y.; Nishiyama, T.; Yamasaki, Y.; Kishita, Y.; Fukushige, S. Proposal of sustainable society scenario simulator. CIRP J. Manuf. Sci. Technol. 2009, 1, 272-278.

41. Beumer, C.; Martens, P. Noah's ark or world wild web? Cultural perspectives in global scenario studies and their function for biodiversity conservation in a Changing world. Sustainability 2010, 2, 2311-3238.

42. Happes, G.; Ishikawa, M. Eco-efficiency guiding micro-level actions towards sustainability: Ten basic steps for analysis. Ecol. Econ. 2009, 68, 1687-1700.

43. Hertwich, E. Consumption and the rebound effect. J. Ind. Ecol. 2005, 9, 85-98.

44. Hondo, Y.; Kobayashi, H. An estimation method of rebound effect based on entropy principle. J. LCA Jpn. 2009, 5, 122-130 (In Japanese). (The English abstract can be found on web, http://www.springerlink.com/content/h872386411370817/)

(C) 2011 by the authors; licensee MDPI, Basel, Switzerland. This article is an open access article distributed under the terms and conditions of the Creative Commons Attribution license (http://creativecommons.org/licenses/by/3.0/). 